Supplement of Solid Earth, 11, 2487-2497, 2020

https://doi.org/10.5194/se-11-2487-2020-supplement

(C) Author(s) 2020. This work is distributed under

the Creative Commons Attribution 4.0 License.

(c) (i)

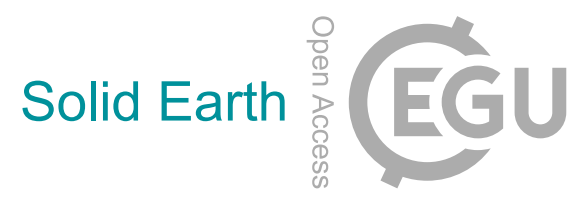

Supplement of

\title{
In situ hydromechanical responses during well drilling recorded by fiber- optic distributed strain sensing
}

\section{Yi Zhang et al.}

Correspondence to: Yi Zhang (zhangyi@rite.or.jp)

The copyright of individual parts of the supplement might differ from the CC BY 4.0 License. 


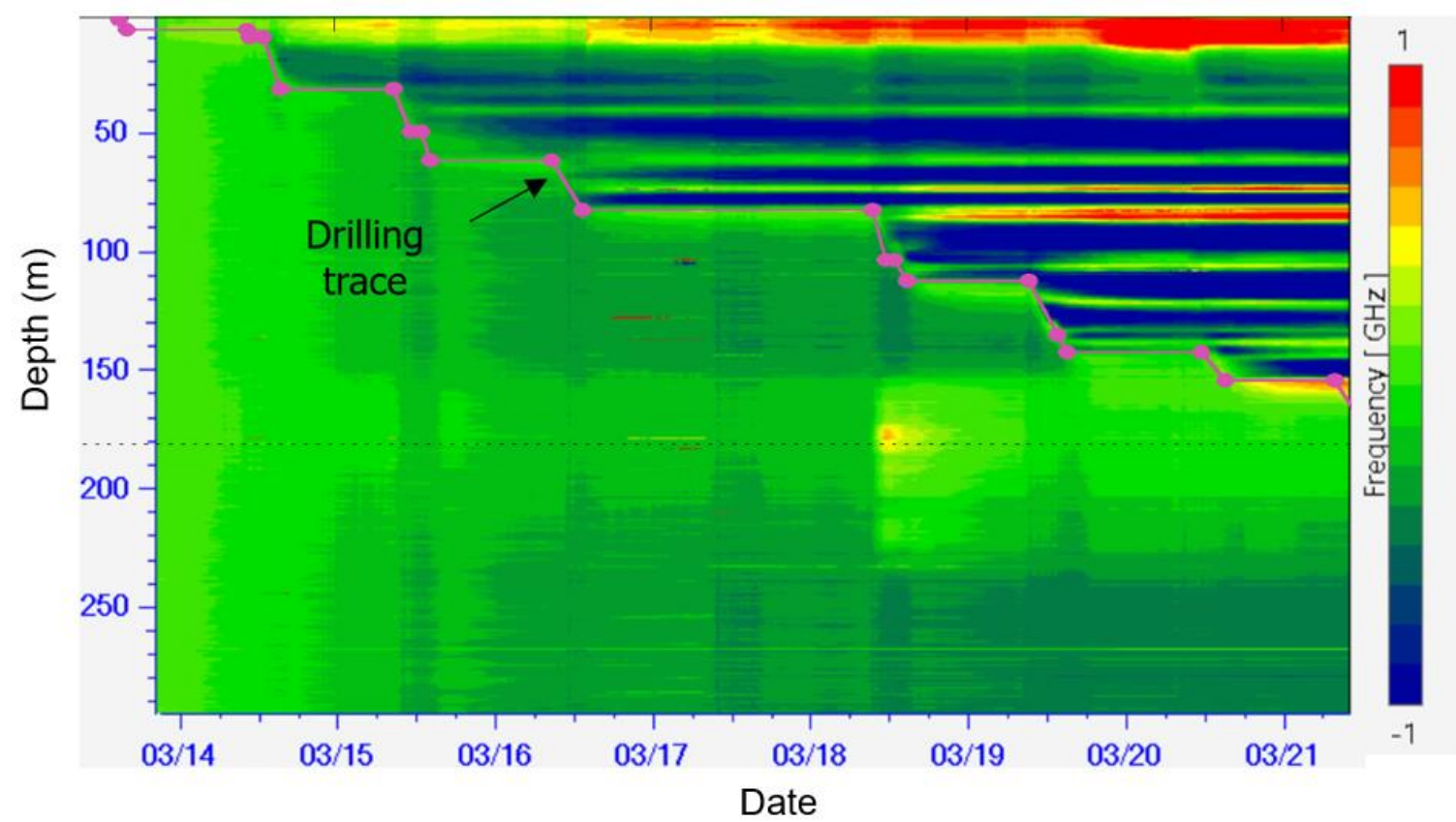

Figure S1. Strain records (shown by the frequency change) at well obs1 with the depiction of the drilling progress.
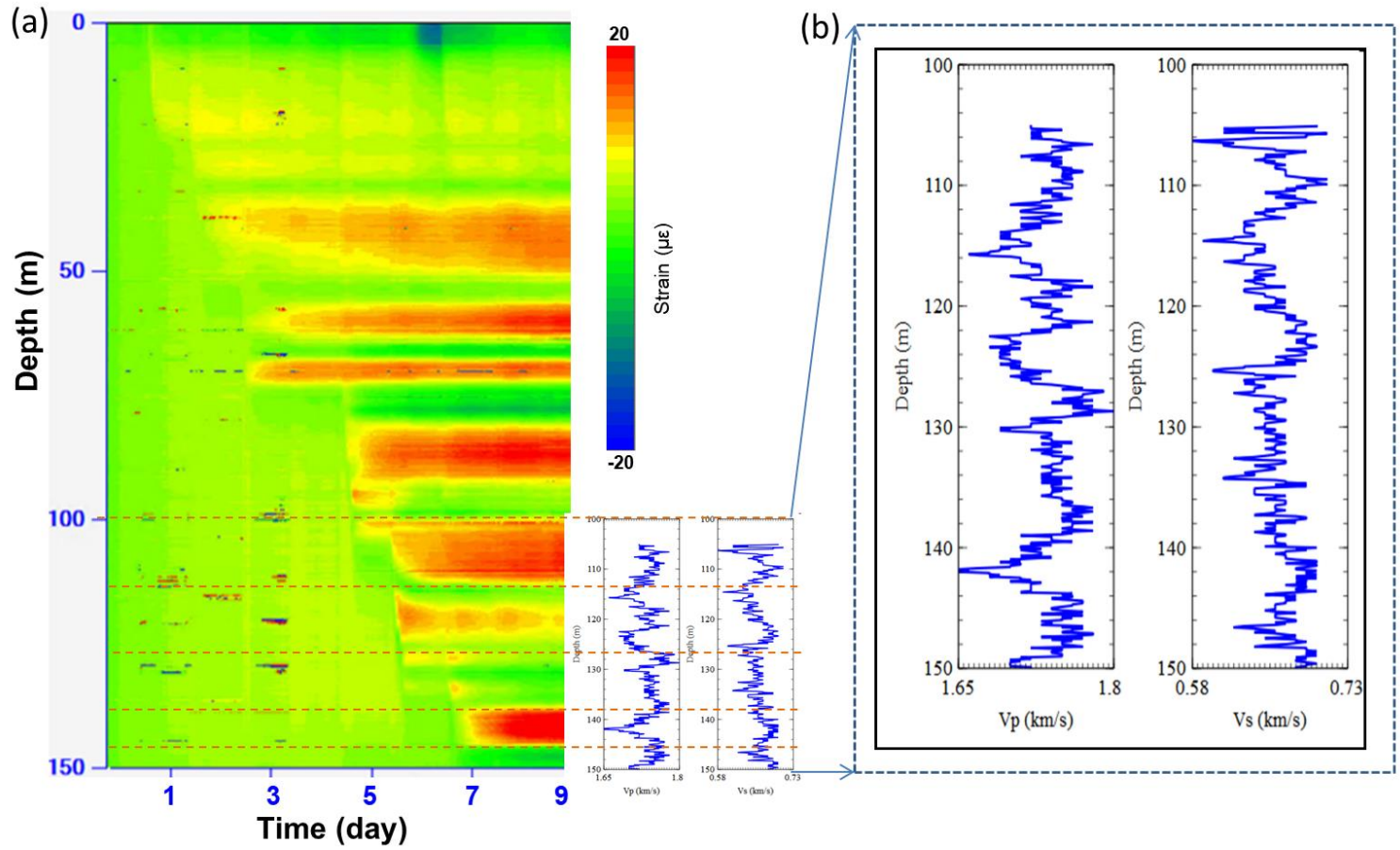

Figure S2. Image of strain changes with time and depth at (a) well obs1 and (b) the well logs of compressive and shear wave velocities ( $V p$ and $V s$ ). 


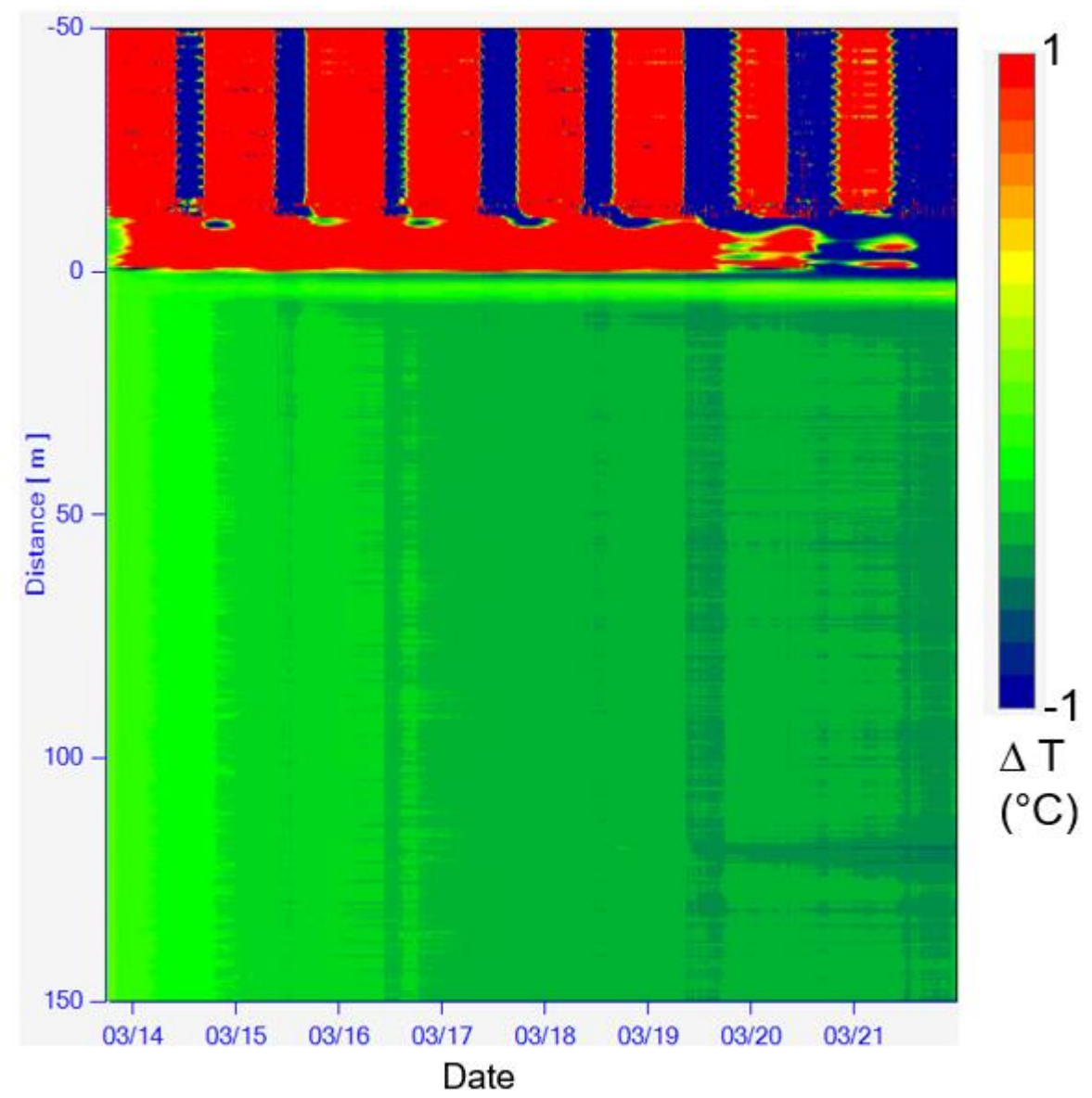

Figure S3. Image of temperature changes with time and depth at well obs1. There are obvious changes in the fibre length on the surface whereas only slight changes are in the fibre in the well. 